\title{
Zero-Emission Hybrid Electric System: Estimated Speed to Prioritize Energy Demand for Transport Applications
}

\author{
Salsabil Gherairi* \\ *Department of Computer and Information Technology, Jeddah Community College, King Abdulaziz University, 21589 \\ (salsabil.gherairi@gmail.com)
}

\$ Salsabil Gherairi, 21589, Tel: +966 566130 478, sghrairi@kau.edu.sa

Received: xx.xx.xxxx Accepted:xx.xx.xxxx

\begin{abstract}
One of the most exciting problems due to its ability to integrate hydrogen as a fuel is Hybrid Electric System (HES), supported by Proton Exchange Membrane Fuel Cell (PEMFC) and Super-capacitors. The Fuel Cell (FC) was chosen to replace traditional energy sources such as batteries and diesel as an attractive technology. PEMFC has not been able to meet the demand for loading and responding to continuous power requirements. The Supercapacitor (SC) has been chosen as an effective means of compensating for transient energy. For this purpose, a precise Energy Management System (EMS) has been proposed using a Fuzzy Logic Controller (FLC). In addition to coordinate the necessary power between the proposed design and the power source. Depending on Supercapacitor State of Charge (SOCsc), energy demand, vehicle speed, and road traffic data (such as map and GPS), the proposed power management system tends to correct the energy demand.
\end{abstract}

Keywords Proton Exchange Membrane Fuel Cell, Super-capacitor Bank, State Space Representation, Energy Management.

\section{Introduction}

So far, the main issues of air pollution in big countries are caused mainly by transport. Furthermore, energy storage systems, usual batteries, are fully aware of the needs of customers and have responded by offering a package perfectly suited to electric vehicles. As a result, abandoned batteries become terrible sources of environmental poison. The use of batteries on transport is limited because of its loading problems [1]. The Fuel Cell Electric Vehicle (FCEV) is considered the best alternative generator with the energy required by the vehicle $[2,3]$. FCEV is a matter of discretionary study that ensures electricity supply and its advantages (such as small noise, small exhaust emissions, natural processing, gas selection, and high efficiency) $[4,5]$ [6]. Because of low operating temperatures and high energy density, PEMFCs can be successful candidates for automotive applications between different FC technologies $[5,6]$. Implementing PEMFC as an energy resource is a significant constraint. As a result, due to the slow dynamic response, $\mathrm{FC}$ was unable to match the supply/demand for the rapidly changing load $[7,8]$. In order to achieve these requirements, most FCEV design relies on PEMFC hybridization with bridge strength (such as Ultracapacitor (UC), battery) using the Power Management Module (PMU) [9]. UC is the best solution for resolving PEMFCs support limits.

Consequently, this system was used to help FC, recovering energy from renewable brakes and provide a peak of supply/demand. In this paper, we aimed to study electrical behaviors, to reduce hydrogen consumption and obtain reliable and straightforward solution energy by combing PEMFC and UC [10]. The importance of energy management strategy is emphasized by some perspectives and difficulties in FCEV device studies using energy storage. Various ways in literature were explored. In [10], the authors proposed an effective hybridization between batteries and energy treatment systems (Supercapacitor) using PEMFC as a critical input to keep them working and reduce hydrogen consumption. To reduce energy loss, the authors used an obscure moderator to develop an online reference [11]. The suggested hybrid energy storage system is used for different applications [12]. The proposed system is intended to combine lithium battery and ultra-power distribution. The 
power management strategy, including four operating techniques (such as high energy, low energy, ordinary control, and charging techniques), focuses primarily on the command required in the application [13], Consecutive about the optimal control approach for FCEV power leadership [14]. The authors in [15] provided incorporation of the energy storage device in the FCEV to improve its transient response and efficiency. As a consequence, the petrol tank scheme with transformation effectiveness of $30 \%$ able to reach a higher standard than the inner combustion scheme. In [16], the authors suggested an energy management strategy using at the same moment, two methods of transformation of wavelets and neural networks.

Compared to the above studies, we proposed an efficient Energy management unit based on various constraints. The proposed approach to control the energy demand during the peak periods and distribute energy production among three sources (PEMFC, BT, and UC). Several challenges will be presented and discussed related to a new zero-emission hybrid electric vehicle. The presented challenges are given as follow:

$>$ Control the system operation with rationalizing energy consumption.

$>$ The system and its components: Most researchers use a battery as a storage medium. However, in our work, we replace the battery with storage of energy (UC) which is considered as higher and faster.

$>$ Strategies applied for energy management: the majority of research requires that the Unified Communications SoC of UC can be used as a vital element of the control strategy. An improvement made by our work by controlling the components of the system via the idiot and the estimated speed via GPS and Google Map Card. This improvement ensures fast interaction against fluctuations.

$>$ The overall efficiency of the system: Our work evaluates the system ability (some research articles ignore the system efficiency)

$>$ FCEV is evaluated and simulated in the realistic context of energy billing vehicles according to a Roadmap and traffic modelling using SUMO (Urban Mobility Simulation).

The paper is organized as follows. Section 2 describes the configuration and modeling of the hybrid power scheme. The proposed energy management system is shown in Section 3. The results of the simulation have been evaluated and discussed in Section 4. Section 5 concludes the paper.

\section{Description of FCFV system}

\subsection{Design of the global system}

In the system studied by Fig. 1, an effective design based on PEMFC and UC is presented. PEMFC is an energy source that plays a significant role as a relief. UC is energy storage considered as an auxiliary source to prevent and optimize the degradation of the PEMFC stack. Both sources are connected via two transformer controllers to efficiently exchange the power demand of the vehicle with the DC bus. The converters are needed to process the output power of the PEMFCs and CPUs by providing the requested power/supply at a constant voltage on the DC bus. A power exchange strategy is suggested for the energy management unit to achieve high efficiency without degrading the performance of the device as well as avoiding rapid adjustments in power demand. The EMS, then, provided the PEMFC with a safe and transient working situation, based on SOCUC and car speed. The speed of calculation is given by a particular speed calculation device to obtain different situations for the vehicle charging.

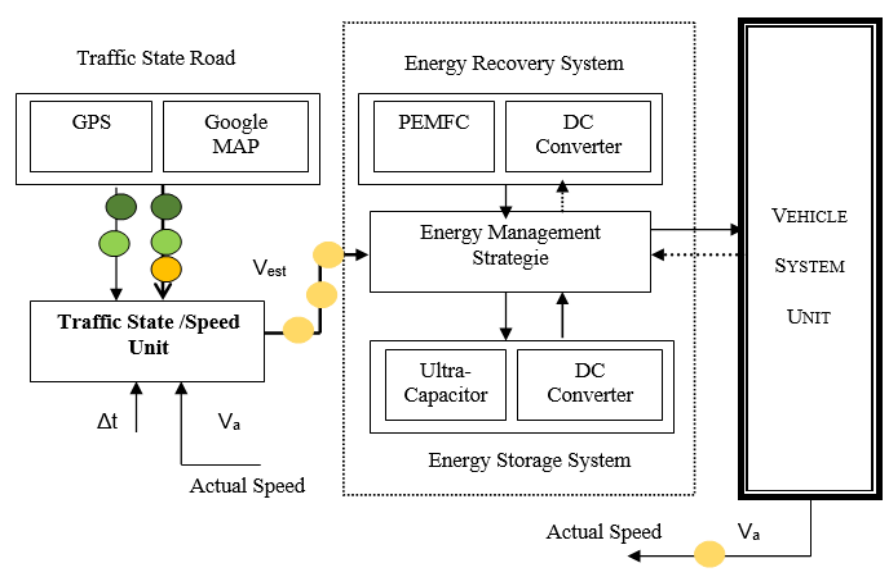

Fig. 1. Configuration of PEMFC-UC powered hybrid system for the vehicle.

Until recently, the battery was the best choice for power supply and small electrical energy storage and could release a constant voltage. Inefficient use of driving power is one of the biggest limitations of the battery, enhancing the competitiveness of the UC [17, 18]. The Ultracapacitor charging cycle is shown in Fig. 2.

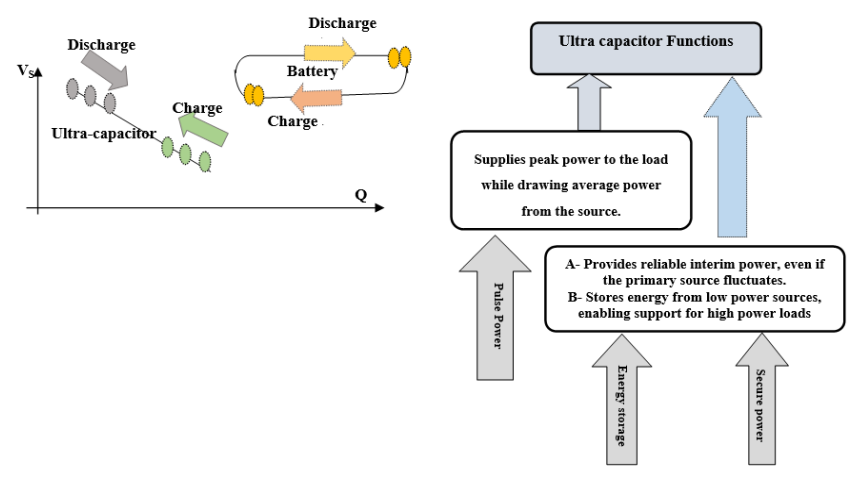

Fig. 2. Schematic of UC power function

The PEMFC device is a primary source that is directly connected to the DC-DC boost converter. The boosters generate a yield voltage by charging the input inductor with fluid from the input voltage source. Subsequently, these inductive circuits are discharged into the input capacitor [19] [20]. The operating voltage (often called VFC) of a given cell can be calculated by mixing the open-circuit voltage, the impact trigger, the Ohm resistance, and the concentration. This voltage is given by Eq. (1). 


$$
V_{\text {PEMFC }}=\sum_{j}^{n} V_{m}=E_{\text {Nernst }}-v_{a}-v_{\text {ohm }}-v_{\text {con }}
$$

The DC/DC booster maintains PEMFC power stability in load variation and provides a power connection between PEMFC and DC bus. PEMFC uses the PI controller via the output current (see Fig. 3). The current control loop [21, 22] adjusts this adapter. PEMFC achievement can be calculated by taking into account all the above results presented by Eq. (2).



Fig. 3. Schematic of the PEMFC/DC-DC converter power module.

Figure 4 shows the electrical diagram of the UCap. UC is a fast-charging/discharging device and high current charging and discharging. Also, it can be achieved without any damage because it is used to achieve good system performance. The relationship between the current and voltage is expressed by Eq. (3) [23].

$$
\left\{\begin{array}{l}
U_{U C}=R_{S} \cdot I_{S} \cdot \frac{1}{C} \int_{0}^{t}\left(I_{U C}-I_{U C}^{D H}\right) \cdot d t+U_{U C}(0) \\
S O C_{U C}=\frac{E_{\max }-E_{\min }}{E_{\max }}=\frac{1}{1-D_{\max }{ }^{2}}\left(\frac{V_{U C^{2}}^{2}}{V^{2}{ }_{U C_{-} \max }}-D_{\max }{ }^{2}\right)
\end{array}\right.
$$

\section{SOC: State of Charge of the UCap}

One limitation to the size of the proposed hybrid-electric system is related to the SOCsc limits. Energy efficiency can be expressed in UCap as a function of discharge time (TD) given by Eq. (4) [24].

$$
\left\{\begin{array}{l}
\eta_{U C}=1-2 R_{U C} C_{U C} \times \frac{1}{T_{D}} \times \frac{\left(1-D_{\max }\right)}{\left(1+D_{\max }\right)} \\
T_{D}=C_{U C} \frac{V_{U C_{-} \max }\left(1-D_{\max }\right)}{I_{U C}}
\end{array}\right.
$$

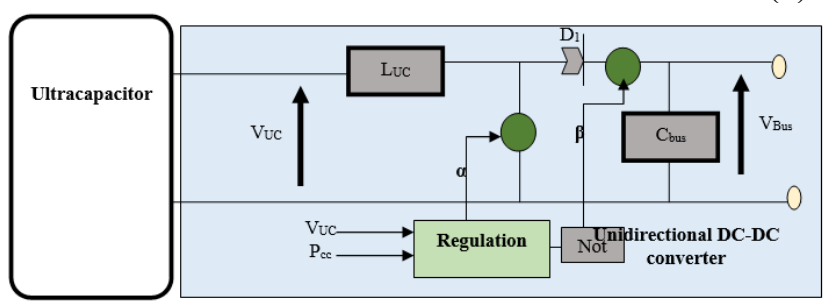

Fig. 4. Schematic of the UC/DC-DC converter power module.

\subsection{The dynamic model of electric vehicle}

The vibrant electric vehicle design is suggested for the efficiency of an electric vehicle. This model, therefore, includes two primary components, the vehicle scheme, and the electrical scheme, both of which must be resolved (see Fig. 5). The modeling and evaluation of these components will be focused on all resources and parameters. It should be mentioned that the speed of the car depends on the energy supplied by both the PEMFC and the UC. The strength of the corresponding resistance is the sum of aerodynamic resistance forces (FAr) and rolling resistance (FRr). The power of the wheel is determined by the performance of the drive and the power supply/demand, simultaneously [25]. The aerodynamic and rolling resistances are given by Eq. (5).

$$
\left\{\begin{array}{l}
F_{A_{r}}=\frac{1}{2} \cdot \rho_{A} \cdot C_{x} \cdot S \cdot\left(V_{s}\right)^{2} \\
F_{R_{r}}=m \cdot g \cdot f_{0} \\
F_{S}=m \cdot g \cdot \sin (\phi)
\end{array}\right.
$$

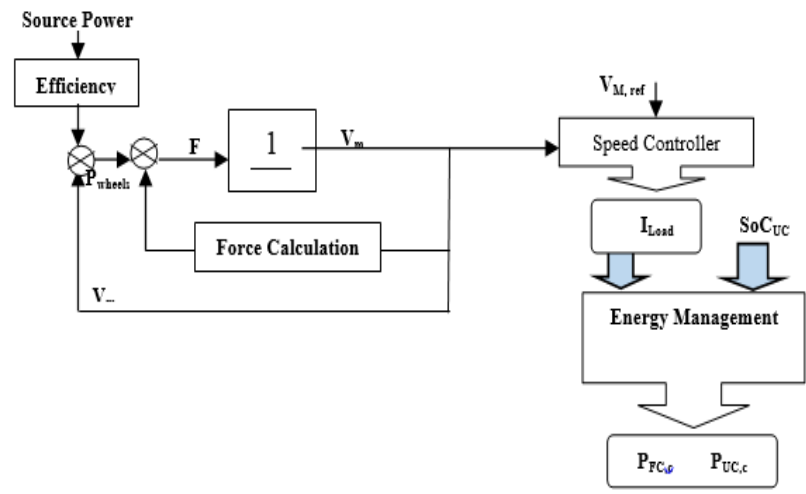

Fig. 5. Schematic of the PEMFC/DC-DC converter power module.

The regulation and installation of DC bus voltage throughout the UCap in EMS is ensured by calculating the power error (often called PR). Error Square Square (often called ESS is a measure of how close the processed line is to the data state. ER and MSR are given by Eq. (6) [26]:

$$
\left\{\begin{array}{l}
M S E=\sum_{t=0}^{t=192}\left(P_{\text {Load }}(t)-P_{\text {Source }}(t)\right)^{2} \\
E R=P_{\text {Load }}-P_{\text {Source }}
\end{array}\right.
$$

\section{Energy Management System}

\subsection{Operational Energy Management}

An Energy Management System (EMS) is used to monitor, control, and improve the performance of the production system. In our case, the proposed EMS should meet load requirements following PEMFC and UC orders. The UC will provide an important solution such as energy storage with power brakes. The FCEV system is controlled according to the charging status and the computing speed level that can determine the system status. The block diagram given by Fig. 6 shows the behavior of the system during the 
activation and deactivation of the source and control blocks. The proposed supervision algorithms can range in different situations:

State 1: Describes the maximum power required by the UC. So, when (SoC $>=$ SoCmax) or $(\mathrm{Ve}>\mathrm{Vm}-\mathrm{min})$ then (IL $<$ IUC-max). In this case, the UCand PEMFC are connected to meet solely provides the necessary load demand $((\mathrm{Ds}=1 ; \mathrm{Is}=\mathrm{Is}-\mathrm{max}))$ and $(\mathrm{DF}=1) ; \mathrm{IF}=\mathrm{IL}-\mathrm{Is}-\mathrm{max})$.

$>$ State 2: Describes the minimum power required by the PEMFC. In opposite case, when (SoC $>=$ SoCmax) or (Ve $<$ Va-min) then (IL $>$ IUC-max). UC is connected to meet solely provides the necessary load demand, based on both load demand and minimum power of PEMFC ( $\mathrm{Ds}=1)$; $\mathrm{Is}=\mathrm{IL}-\mathrm{IFC}-\mathrm{min})$ and $(\mathrm{DF}=1)$.

State 3: Presents the maximum power required by FC. This state depends only of to the state of charge and speed. When (SoC $<$ SoCmin) Or $(\mathrm{Ve}<\mathrm{Vm}$-max $)$ Or $\mathrm{Ve}>\mathrm{Vm}-$ max) then (IL> IF-max). The PEMFC is connected to provide the energy demand $(\mathrm{DF}=1$ and $\mathrm{IF}=\mathrm{IF}-\mathrm{max})$, and the $\mathrm{UC}$ remains up $(\mathrm{DS}=1 ; \mathrm{IL}=\mathrm{IF}+\mathrm{Is})$.

$>$ State 4: Describes the minimum power required by UC. When (SoC $<$ SoCmin or Vest $<$ Va-max) then (IL $<$ IFmax). The power demand depends only on both the PEMFC power and the minimum power of UC. PEMFC is connected to offer the power demand $(\mathrm{DF}=1 ; \mathrm{IL}=\mathrm{IF}+\mathrm{Is}-\mathrm{min})$, and the $\mathrm{UC}$ remains up to provide the minimum power ( $\mathrm{DS}=1)$; $\mathrm{IS}=$ Is-min).

State 5 and 6: Describes the power recover power required by $\mathrm{SC}$. So, when $(\mathrm{SoC}<100 \%$ and $\mathrm{SoC}<100 \%)$ the UC to meet solely provides the necessary load demand $((\mathrm{DS}=1) ; \mathrm{IL}=\mathrm{IS})$. While The PEMFC remains off $(\mathrm{DF}=0)$.

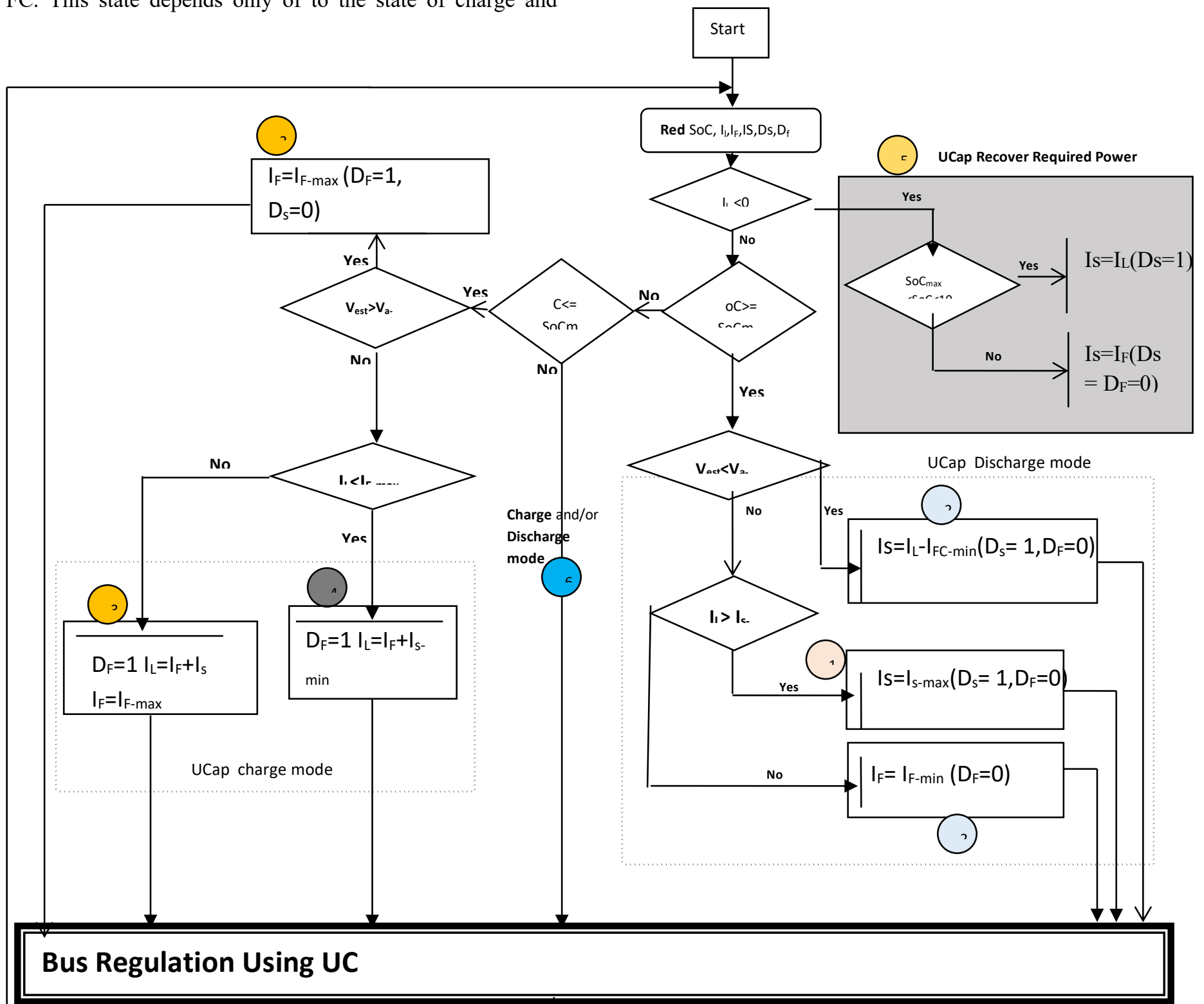

Fig. 6. Operational Energy Management 


\subsection{Fuzzy Logic Rules}

The control strategy is based primarily on the adopted conclusions, which are evident by the language description and the base number. Each rule has a precondition. FLC aims to improve the distribution strength between PEMFC and SC and the electrical load. FLC was chosen to ensure the best running of the engine in the optimum power range. Therefore, the linguistic description of the adopted reasoning can be described and discussed in three ways described as follows:

Acceleration mode: Vact, Vest, and SoCSC are input signals. Pfcc is the output signal. The new acceleration mode strategy is displayed in the FL rules. Comparison of actual and estimated speed for the SC charging status. Thus,
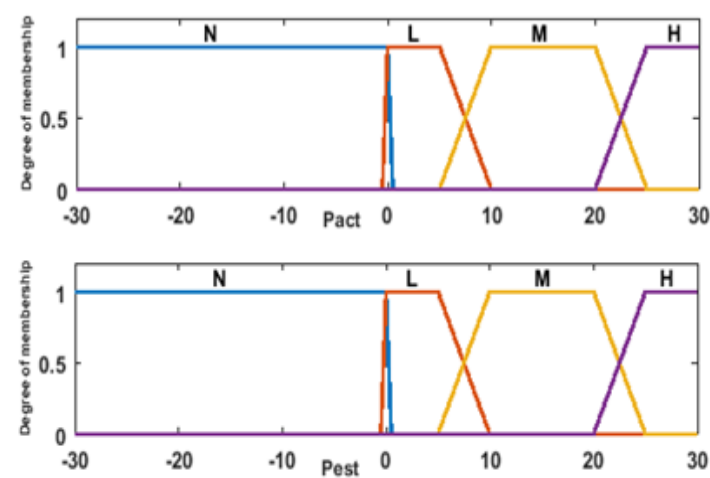

Fig. 7. Input/output variable functions of the Fuzzy-Logic online power management. in this mode, knowing the speed at $(t+d t)$ allows SC to use its stored energy based on the data in $(t+d t)$. Using recognition speed like new inputs in FL can ensure the best

Fixed speed model: Fixed speed mode is displayed in FLC rules. The use of the predicted data, the fuel cell can provide excess power to move the electric vehicle and charge the SC. In the opposite case, the fuel cell provides less energy than the energy required to discharge the SC.

Braking Mode: Braking mode is displayed in FLC rules. This model relies on the SoCSC of the SC and the rated speed. If SoCSC is not high, SC will charge at $t+d t$. Therefore, SC provides power to the vehicle depending on the charging status at $(t+d t)$.
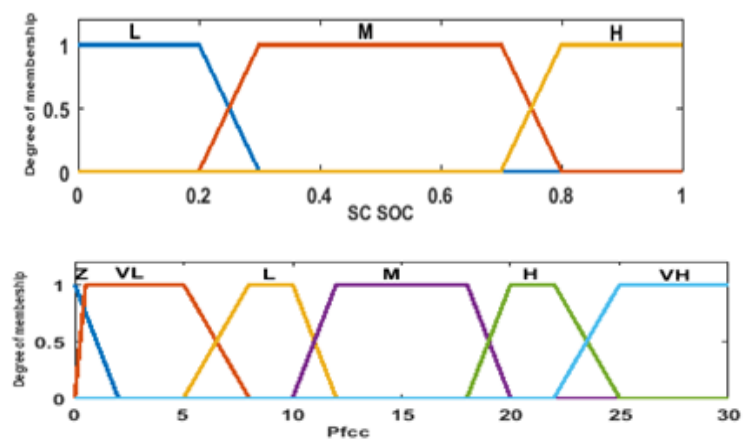

correlation model of the proposed PEMFC/UCap hybrid power system.

In our simulations, we selected the status of the car traffic model in the Manar area of the Tunisian city (see Fig. 8). It is located near the University of Tunis El Manar, and the region has a wide range of about $2.5 \mathrm{~km}$. The default speed of the vehicle is about $50 \mathrm{~km} / \mathrm{h}$, and the density is linked to one vehicle per second added to this area.

The mysterious logic system was applied using three input variables, namely Actual Power (PAct), Rated Power (PEst), and SC Charging Status (SOCSC). The resulting variable of the system is the reference energy provided by the fuel cell (PFCC). A fuzzy rule-based controller provides distribution power between PEMFC and SC. The power that PEMFC provides depends on the control of SOCSC, PAct, and PEst. These parameters will be sterilized using a cellular function (see Fig. 8). In this work, trapezoidal organic functions were chosen because of their commonly used form than the others. The proposed system can make proper energy management, according to the actual speed and the next (estimated) speed according to road traffic data. This information is collected from the online Map service such as the MapQuest APIs or the Google API and according to the actual situation using GPS [27]. Thus, we can predict the future energy load needed for the vehicle by changing the estimated future speed according to the traffic contained in the API (see Fig. 8). The proposed system contains an 
energy management program that is carried out as a periodic task or operations every period. After reading the signal data from different power subsystems (PEMFC and Super-Capacitor), this program will decide on how to activate the power subsystems.
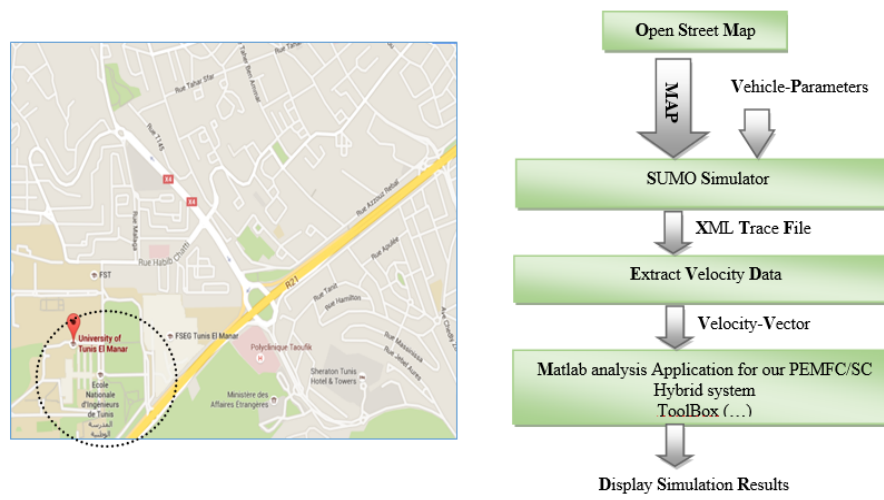

Fig. 8. Simulation Modules

\subsection{Hybrid system Evaluation using a predicted velocity}

In this section, EMS performance is evaluated. The proposed hybrid system is handled through different simulation scenarios based on a realistic traffic model. The results are obtained by Matlab/Simulink and SUMO. The traffic to be handled by Al Manar Roadmap has radium of $2.5 \mathrm{~km} / 200 \mathrm{sec}$ and a vehicle speed of about $50 \mathrm{~km} / \mathrm{h}$. In our results, we considered that every single second, a new car would arrive in the same area. PEMFC and SC have the power of $30 \mathrm{KW}$ and $20 \mathrm{KW}$, respectively. Actual speed, estimated speed, and SC shipping status are obtained via a Web server (WSM). The colors are given by Fig. 9 distinguish the levels of traffic congestion. For example, the red color denotes that the traffic on the road is weighty.

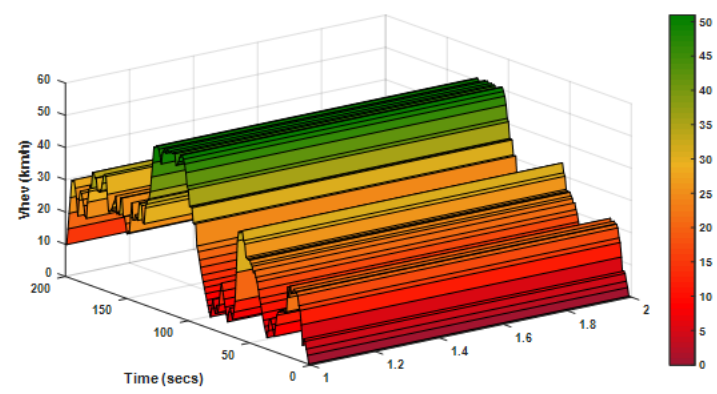

Fig. 9. Considered Speed Profile

The results obtained are found in the details of our applicable control efficiency, which are used to solve slow PEMFC dynamics and to avoid load fluctuation (see Fig. 10). The proposed control allows the fuel output (PM 400 IFC $=400 \mathrm{~A}$ ) to be synchronized with the DC bus current (IFC/Boost $=50 \mathrm{~A})$. The results of currents obtained before/after the regulation show that the current SC reaction reacts immediately to meet the transient demand for electric power. Additionally, these results prove the performance of the control strategy and the efficiency of the PI regulator.



(a)

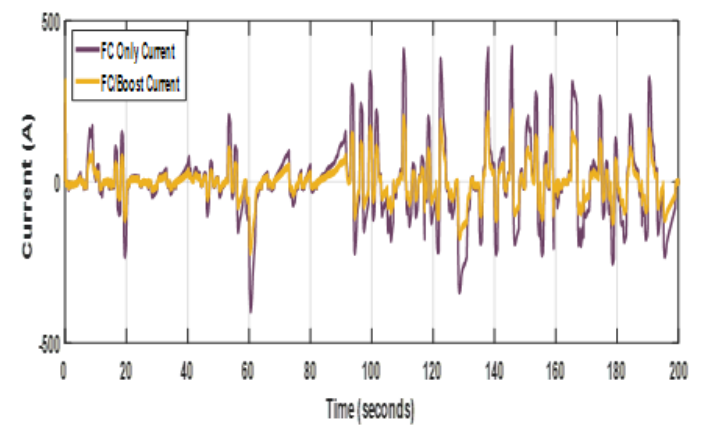

(b)

Fig. 10. FC/SC Currents: (a) before control, (b) after Control

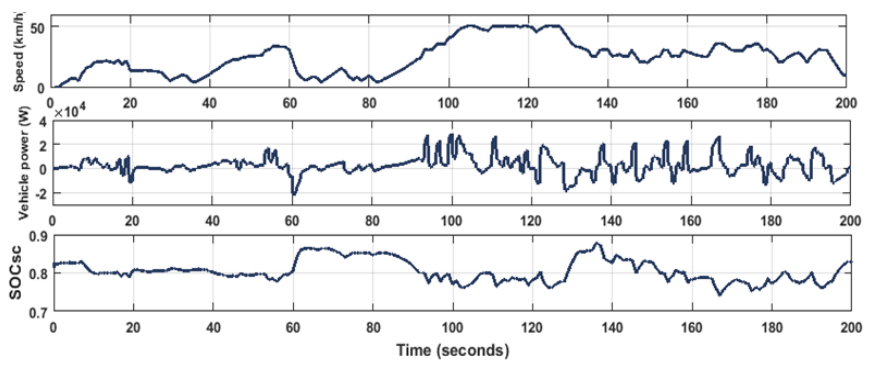

Fig.11. Traffic Level, Vehicle Actual speed, Actual power and SC state of charge

Case A: During [53, 54], [93, 94] and [136, 138] when the system running in acceleration mode, SC provides higher power than PEMFC according to its charging state to maintain optimal operation of the fuel cell, depending on Rated Vehicle Power.

$>$ Case B: When the system is operating in braking mode, $\mathrm{SC}(\mathrm{SC}=\mathrm{ON})$ is charged until the $\mathrm{SC}$ charging state reaches its maximum level.

Case C: When the system operates in fixed speed mode, PEMFC can only supply the power needed by the vehicle even if the SoCSC is high, because in the following case if the mode is acceleration; $\mathrm{SC}$ is discharged otherwise means there is a state of braking, 
Thus PEMFC is loaded which verifies our results in the range $[28,32]$.



Fig. 12. Vehicle Actual and Estimated data

\section{Conclusion}

This paper proposes the proposed and evaluated PEMFC/SC hybrid electrical system. Energy demand is presented using the PEMFC assessment. To solve transient PEMFC power, an SC/Boost adapter was selected. SC was used to control the absence of energy when PEMFC was extinguished. In addition, it is triggered during peak periods. To improve energy demand and power supply, respectively, we have proposed a precise environmental management system using FLC. According to Google's online map service and energy demand, the actual speed, speed is estimated. The EMS has been processed and explained through a pilot electrical load profile, online GPS service, and vehicle speed. The results obtained were found to be the main function of HES during peak periods and peak hours. During the rapid dynamic period, SC provided active force. Future work aims to improve our design, which will be referred to as a real-time system. A second power storage battery will be included. Indeed, we aims to use Raspberry Pi card to implement our proposed approach in an embedded system. This card can provide contrast delay with a critical limit. It gives, also, the suspension of variation with a deterministic limit. Furthermore, Raspberry Pi card has many exciting features for sensor and actuator interface and it is considered as an excellent platform.

\section{References}

[1] Gorantla Srinivasa Rao, G. Kesava Rao, S. Sivanagaraju, G.R.K. Murthy, B.C.N.S. Sudheer, "Automated battery management system for electric/hybrid electric vehicle", International Journal of Electric and Hybrid Vehicles, DOI: 10.1504/IJEHV.2011.042143, 2011, Vol.3, No.2, pp.123 - 137

[2] Gorantla Srinivasa Rao * Gattu Kesava Rao Sirigiri Siva Naga Raju, "An innovative approach to battery management and propulsion system of electric/hybrid electric vehicle", 2014, Vol. 6, pp.1-13.

[3] X.H. Zeng, L.W. Nie, and Q.N. Wang, "Experimental. Study on the Differential Hybrid System Hybrid Electric Vehicle", Procedia Engineering, 2011, Vol. 16, pp. 708- 715
[4] Jehad Yamin, Mohammad Hamdan, Simulation of an electrical engine powered by fuel cell-solar energy hybrid system, International Journal of Electric and Hybrid Vehicles, DOI: 10.1504/IJEHV.2010.034983, 2010 Vol.2 No.4, pp.308 - 314.

[5] Mahnaz Rashedi and Mohsen Mohammadian. "Online Energy management applied to fuel cell hybrid electric vehicles", International Journal of Electric and Hybrid Vehicles, DOI: 10.1504/IJEHV.2010.034984, 2010; Vol. 2, No.4, pp.315 - 328.

[6] Nelson DJ. "Energy Management Power Converters in Hybrid Electric and Fuel Cell Vehicles", Proceedings of the IEEE, Vol. 95, pp.766-777, April 2007.

[7] Chan BCC. "The State of the Art of Electric, Hybrid, and Fuel Cell Vehicles", Proc. IEEE, vol. 95, no. 4, pp. 704-718, 2007.

[8] Subsingha W, Sarakarn P. "Phase Interleaved DC Boost Converter for PEMFC Applications", Procedia Engineering, DOI:10.1016/j.proeng.2012, Vol. 153, pp.1127-1134.

[9] Seyezhai R. "Simulation and Implementation of SoftSwitched Interleaved DC-DC Boost Converter for Fuel Cell Systems", International Journal of Power Electronics and Drive Systems, 2012, Vol. 1, pp 203208.

[10] Jannelli E, Minutillo M, Perna A. "Analysing microcogeneration systems based on LT-PEMFC and HTPEMFC by energy balances". Applied Energy Journal, 2013, Vol. 108, pp.82-91.

[11] Minutillo MÃ, Perna A. "Behaviour modeling of a PEMFC operating on diluted hydrogen feed". Int. J. of Energy Research, DOI:10.1002/er.1424, 2008, Vol. 32, pp. 1297-1308

[12] Nelson RF. "Power requirements for batteries in hybrid electric vehicles", Journal of Power Sources, 2000, Vol. 91, pp.2-26.

[13] Cao J, Emadi A, "A New Battery / UltraCapacitor Hybrid Energy Storage System for Electric, Hybrid, and Plug-In Hybrid Electric Vehicles", IEEE Transactions on Power Electronics, DOI:10.1109/tpel.2011.2151206, 2012, Vol. 27, pp.122-32.

[14] Laldin O, Moshirvaziri M. "Predictive Algorithm for Optimizing Power Flow in Hybrid Ultracapacitor/Battery Storage Systems for Light Electric Vehicles", IEEE TRANSACTIONS ON POWER ELECTRONICS, Vol.28, No. 8, pp. 3882-95, August 2013.

[15] Kisacikoglu MC, Uzunoglu M, Alam MS. "Load sharing using fuzzy logic control in a fuel cell/ultracapacitor hybrid vehicle". Int. J. Hydrogen Energy 2009, Vol. 34, pp. 1497-507.

[16] Lachhab I, Krichen L. "An improved energy management strategy for FC/UC hybrid electric vehicles propelled by motor-wheels". Int. J. Hydrogen 
Energy DOI:10.1016/j.ijhydene.2013.10.064， 2014, Vol. 39, pp. 571-81.

[17] Tani A, Camara MB, Dakyo B, Azzouz Y. "DC/DC and DC/AC Converters Control for Hybrid Electric Vehicles Energy and Fuel Cell", IEEE TRANSACTIONS ON INDUSTRIAL INFORMATICS, Vol. 9, No. 2, pp.686-96, May 2013.

[18] Thounthong P, Raël S, Davat B. "Energy management of fuel cell/battery/supercapacitor hybrid power source for vehicle applications", Journal of Power Sources, 2009, Vol. 193, pp. 376-385.

[19] Shin D, Lee K, Chang N. "Fuel economy analysis of fuel cell and supercapacitor hybrid systems". Int. J. Hydrogen Energy DOI:10.1016/j.ijhydene. 2015.10.103, Vol. 41, pp.1381-90.

[20] Slama B, Sihem N, Zafar B, Adnane C. "Performance study and efficiency improvement of Hybrid Electric System dedicated to transport application". Int. J. Hydrogen Energy 2016:1-13. DOI:10.1016/j.ijhydene.2016.11.145.

[21] Gößling S, Beckhaus P, Heinzel A. "Dynamic PEMFC model as a base for a state classifier and controller", Energy Procedia, DOI:10.1016/j.egypro.2012.08.045, 2012, Vol. 28, pp. 1-198.

[22] Aouzellag H, Ghedamsi K, Aouzellag D. "Energy management and fault-tolerant control strategies for fuel cell/ultra-capacitor hybrid electric vehicles to enhance autonomy, efficiency and lifetime of the fuel cell system", Int J Hydrogen Energy, DOI:10.1016/j.ijhydene.2015.03.132, 2015, Vol. 40, No. 22, pp. 7204-7213.
[23] Shinde PA. "Real-Time Vehicle Monitoring and Tracking System based on embedded Linux board and android application", International Conference on Circuits, Power and Computing Technologies, ppp. 17, 2015.

[24] Allaoua B, Asnoune K, Mebarki B. "Energy management of PEM fuel cell/supercapacitor hybrid power sources for an electric vehicle". Int. J. Hydrogen Energy DOI:10.1016/j.ijhydene, 2017, Vol. 209, pp. 19.

[25] Yu Z, Zinger D, Bose A. "An innovative optimal power allocation strategy for fuel cell, battery and supercapacitor hybrid electric vehicle". Journal Power Sources DOI:10.1016/j.jpowsour.2010.09.057, 2011;196:235, pp1-9.

[26] O. Tremblay, L. Dessaint and A. Dekkiche, "A Generic Battery Model for the Dynamic Simulation of Hybrid Electric Vehicles", IEEE Vehicle Power and Propulsion Conference, DOI:10.1109/vppc.2007.4544139, pp.284-289, 2007.

[27] Jie Zhang Dan Yang, Yaotiao Deng Ying Wang, Lei Deng, Xinmei Luo, Wuning Zhong, Jie Liu, Yuqing Wang, Yu Jiang", The willingness and actual situation of Chinese cancer patients and their family members participating in medical decisionmaking", Psycho-Oncology, 2015, Vol. 24, No. 12, pp. 1663-1669, Available: 10.1002/pon.3835. 